\title{
Advances of Bio Toilets in Railways
}

\author{
Prof. Vinod. P Sakhare ${ }^{1}$, Prof. Arvind Wadgure ${ }^{2}$, Prof. Rahul Sanghi ${ }^{3}$, Prof. Narendra Wadaskar ${ }^{4}$ \\ Dept of Mech Engg, GNIT, Nagpur, India ${ }^{1,2,3}$ \\ Head, Dept of Mech Engg, GNIT, Nagpur, India ${ }^{4}$
}

\begin{abstract}
The usual train toilet systems provided in the Indian Railways discharge the waste directly on to the railway track systems. This leads to infecting the area and spreads a foul smell with unhygienic conditions for the trackmen for inspection and maintenance. By providing some advancements and improvising on the existing waste disposal system, we have built a safe way to conserve water by reusing the water that was once used for flushing by filtering it and again using it for the flushing purpose. This not only conserves water by reducing the overall wastage of water but also saves the tracks from the water that will corrode it. The solid waste can either be anaerobically digested to form fertile soil in the digester or can be compressed and composed into a composite solid waste.
\end{abstract}

Keywords: Railways, Unhygienic, Filtering, Digester, Anaerobically, Composite, Solid Waste.

\section{INTRODUCTION}

On an average, 12617 trains run every day and carries an estimated 23 million passengers daily throughout India. Due to the vast area and huge population that travels every day, there have been concerns over sanitation in railways. The traditional sewage disposal system disposes the waste onto the tracks directly which not only pollutes the environment but also causes rusting of tracks due to the mixture of water present in waste.

Though Indian Railways have been working with bio toilets, but a lot of improvements are still needed in this sector as only around 17,388 conventional toilets have been replaced with bio toilets. The bio toilets still discharge the end process water on the railway tracks which causes corrosion due to the oxidation. The bio toilets were developed by Defense Research and Development Organization (DRDO), have a colony of anaerobic bacteria, kept in a container under the lavatories that convert human waste into water and small amounts of gases. The gases are released into the atmosphere and the water is discharged after chlorination on to the track.

The project work directly focuses on the improvements that could be brought onto the existing waste disposal and treatment systems that have been in existence. To safely reuse the water from the waste after filtering it with proper procedures and then using it for flushing. This will help in saving a lot of precious water and lesser need to refill tanks at stations saving manpower and conserving water with proper optimization.

Sanitation is always regarded as a key of development intervention. Sanitation generally refers to the provision of facilities for disposal of human urine and fecal matter. It deals with maintenance of hygienic conditions through services such as collection and disposal of solid and liquid waste. Several deadly diseases because of lack of sanitation like diarrhea, dysentery, typhoid, malaria and dengue are the outcome of improper or lack of sanitation.

Indian Railways, a fast profit making organization and operates as the most densely utilized train system in the world. Railways cover length and breadth of country through its rails. Sanitation in Indian Railways is a big threat to the image of Indian railways. Poor sanitation conditions are a setback to the progressing Railway sector.

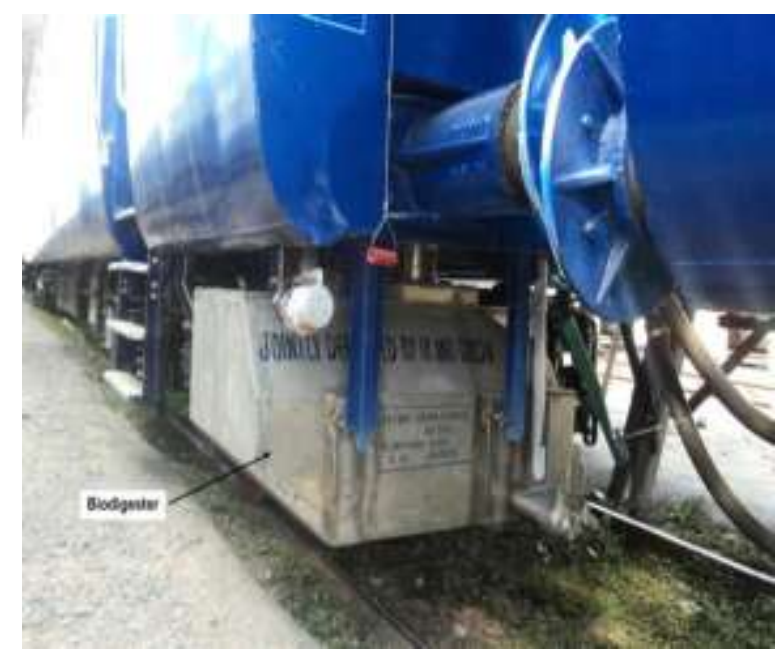




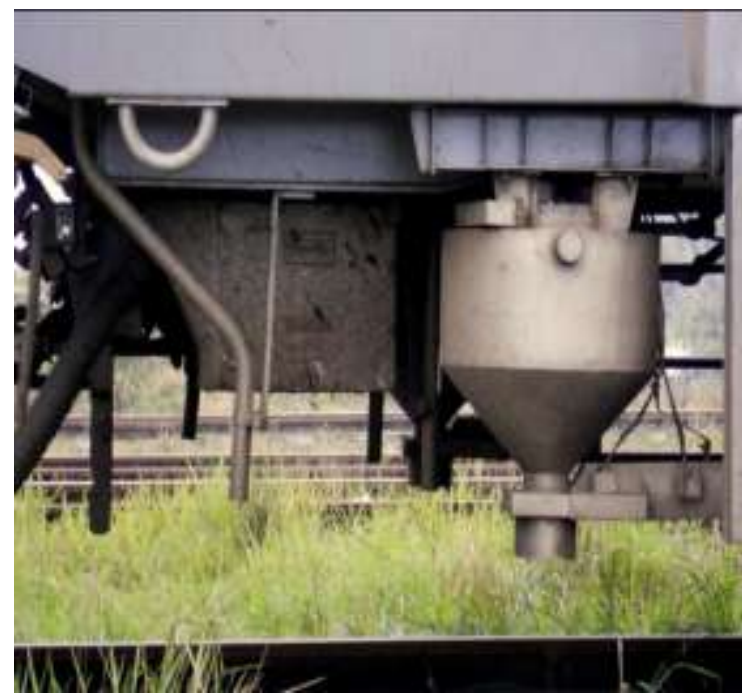

Fig 1 :- Bio Toilet used in Railways

The existing toilet system in the coaches discharges excreta directly to the ground and on the railway tracks. The consequences include unacceptable hygienic conditions, particularly on the railway stations, and damage to rails.

A related socio economic problem is that of people residing near the railway stations, without access to toilet facilities, using tracks for open defecation. Open defecation through railways, unclean toilets, choked basins, litters in bogeys and along tracks are the causes that has compelled us to put a thought over sanitation in railways. This human waste on the railway tracks is the main cause of diseases spreading to nearby settlement areas along with delayed decomposition and contamination of water under bridges. This paper deals with a simple solution which will help in the collection of this waste and further process it to generate fertilizers and bio-gas which can be further used to generate electricity which will be sufficient for lightening purpose on railway stations and nearby household locality also.

\section{MATERIAL USED AND METHODOLOGY}

i) Frame Structure:-

It is made up of M.S angle of dimension,

$\mathrm{L}=700 \mathrm{~mm}, \mathrm{~B}=540 \mathrm{~mm}, \mathrm{H}=1670 \mathrm{~mm}$

All the joints of the structure are properly welded.

From Top at a distance of $320 \mathrm{~mm}$ there is an another frame for holding water tank of size,

$\mathrm{L}=700 \mathrm{~mm}, \mathrm{~W}=540 \mathrm{~mm}$

From the top at a distance of $710 \mathrm{~mm}$ there is another frame for holding toilet seat of size. $\mathrm{L}=700 \mathrm{~mm}, \mathrm{~W}=540 \mathrm{~mm}$

From the bottom at a distance of $30 \mathrm{~mm}$ there is another frame for holding the lower tank of size, $\mathrm{L}=900 \mathrm{~mm}, \mathrm{~W}=540 \mathrm{~mm}$

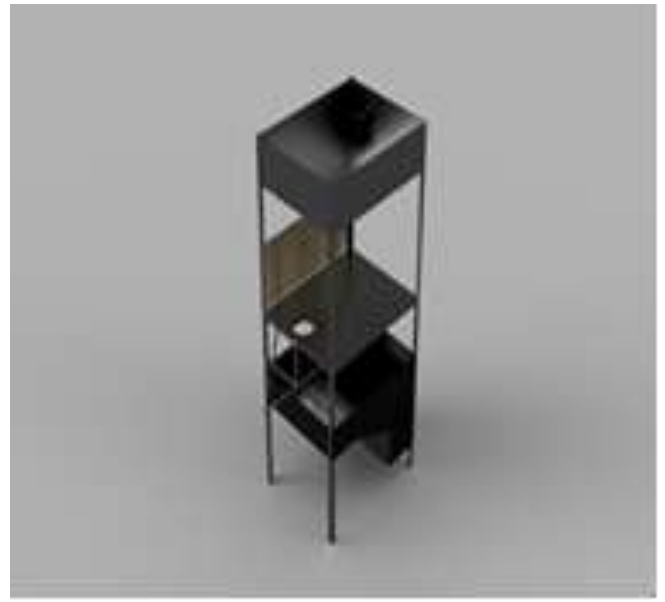




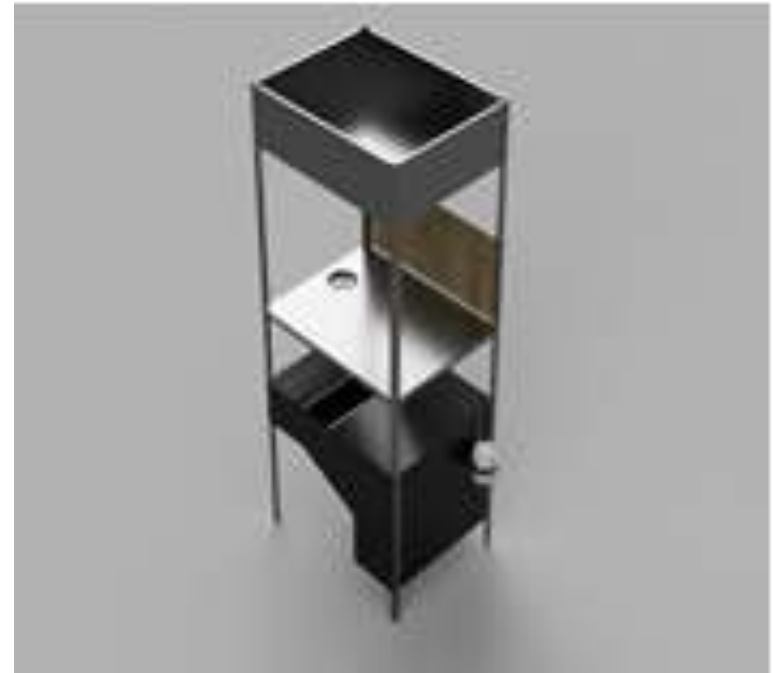

Fig2: - Frame Structure

\section{ii) Tank}

I) Upper tank is made of Galvanized sheet of size,

a) $\mathrm{L}=680 \mathrm{~mm}$

b) $\mathrm{W}=520 \mathrm{~mm}$

c) $\mathrm{H}=180 \mathrm{~mm}$

Capacity of tank $=\mathrm{L} \times \mathrm{W} \times \mathrm{H}$

$=0.064 \mathrm{~m} 3$ or 64 lit.

This tank is only used for storing water.

II) Lower tank is made of M.S sheet of size,

$\mathrm{L}=680 \mathrm{~mm}$

$\mathrm{W}=520 \mathrm{~mm}$

Capacity of tank is 99.4 liters.

But, the filter and screening chamber is also attached to the lower tank. The net used for screening chamber has pores of diameter $1 \mathrm{~mm}$.

\section{1) Piping Connection:-}

The piping connection is made from the upper tank with the pump of diameter $15 \mathrm{~mm}$, length $1500 \mathrm{~mm}$ to toilet seat and from the toilet seat the connection is made of pipe of diameter $25 \mathrm{~mm}$ and length $600 \mathrm{~mm}$ with the lower tank. The next connection is made from the lower tank to the filter of pipe diameter $15 \mathrm{~mm}$ and length $900 \mathrm{~mm}$ and then from filter to the toilet seat of diameter $9 \mathrm{~mm}$ and length $1200 \mathrm{~mm}$

\section{2) 2) Pump :-}

The first pump is attached between the upper tank to the toilet seat having flow rate $18.3 \mathrm{lit} / \mathrm{min}$. The second pump is attached between the lower tank with filter and from filter to the toilet tank having flow rate of $18.3 \mathrm{lit} / \mathrm{min}$. Both the pumps are connected to the electrical circuit

\section{3) Filter:-}

The filter is attached to the filter holder back side of the lower tank and connected with the pipe between the lower tank pump and the toilet seat. Has ability to separate the dust particles of size 0.5 to $1 \mathrm{~mm}$ diameter from the fluid.

\section{4) Shifter Mechanism :-}

The M.S bar is used for fabricating the shifter mechanism as shown in fig. The length of lever is $60 \mathrm{~mm}$ and length of connecting rod is $250 \mathrm{~mm}$. At the end of the connecting rod the M.S pipe of diameter $18 \mathrm{~mm}$ is welded perpendicular to the welding rod. If the lever is pushed in anti-clockwise direction and then the direction of the flow changes. The flow is directed towards the outlet to the funnel 2. In this case the lever angle is $120 \mathrm{deg}$. If the lever is pushed in clockwise direction, then the flow is directed in the tank from funnel 1 . In the 2 nd case, the lever is perpendicular to the connecting rod.

\section{5) Toilet Seat :-}

The toilet seat is placed over the aluminum sheet frame of size $700 \mathrm{~mm}$ length and $540 \mathrm{~mm}$ width between the lower and the upper tank at a height of $710 \mathrm{~mm}$ from the top.

\section{6) Circuit :-}

As shown in the figure the supply is given to the MCB and then to the relay logic. As the input from the push button is given to the relay logic, it indicates the timer for supplying current. The timer provides the output by operating first the 
lower pump for the $4 \mathrm{sec}$ and then after 4 seconds the lower pump is off, and then after the upper tank pump is activated for the next 5 seconds and after the 5 seconds the pump is automatically off. In this way the overall circuit works. The sensor alarm is fitted with a circuit which indicates with sound when the tank is completely filled.

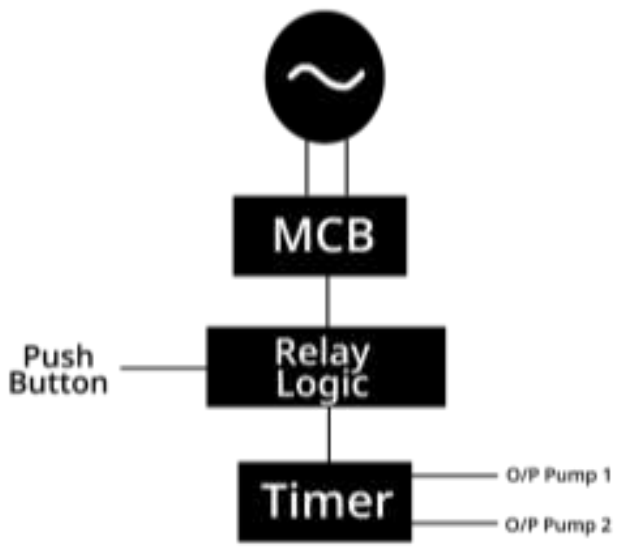

Fig3: - Description of Circuit

\section{MACHINE DESCRIPTION AND OPERATION}

Flushing Unit:-As the push button is pressed, it activates the relay logic. The relay supplies the current to both timers. The first timer activates the lower tank pump for the first 3 seconds and the flow rate is 0.915 lit and stops after 3 seconds, and then after 3 seconds the second timer activates and supplies the current for the next 5 seconds and the flow rate is 1.525 lit and then the overall unit stops after 8 seconds. The total amount of water flow in 8 seconds is 2.44 lit.

Shifter Mechanism:- If the lever of shifter mechanism is perpendicular, that is 90 to the connecting rod, then the direction of flow from the toilet seat is in bio chamber. Now if the shifter is rotated at anti-clock wise 130 to the connecting rod the direction of flow changes that is the flow is directed out of the tank.

Filteration Unit:-The water available at the outlet of bio digester ranges from PH value 6 to 9 and the water is chlorinated in tank itself, the water is also odour less but it contains some waste particulates with it. So when system is activated the pump supplies the water to filter from which the waste particulates from the water is separated and then the water is supplied for the flushing at very less volume.

\section{DESIGN AND CALCULATIONS OF MACHINE}

1) Maximum head of pump $=1850 \mathrm{~mm}$

Therefore, pressure available is $\mathrm{P}=\mathrm{Pgh}$

$\mathrm{P}=1000 * 9.81 * 1.850$

$=188148.5 \mathrm{~N} / \mathrm{m} 2$

$=18.148 \mathrm{Kpa}$

2) Velocity of water

$\mathrm{V}=\mathrm{Q} / 3600 * 3.14 *(\mathrm{~d} / 2) 2$

$\mathrm{V}=1.1 / 3600 * 3.14 *(0.015 / 2) 2$

$\mathrm{V}=1.72 \mathrm{~m} / \mathrm{s}$

3) Volume

i) UPPER TANK

$=\mathrm{LxBxH}$

$=0.68 * 0.520 * 0.18$

$=0.064 \mathrm{~m} 3$

$=64$ lit.

ii) LOWER TANK

1) $\mathrm{L} \times \mathrm{B} \times \mathrm{H}$

$=0.2 \times 0.52 \times 0.16$

$=0.01664 \mathrm{~m} 3$ 


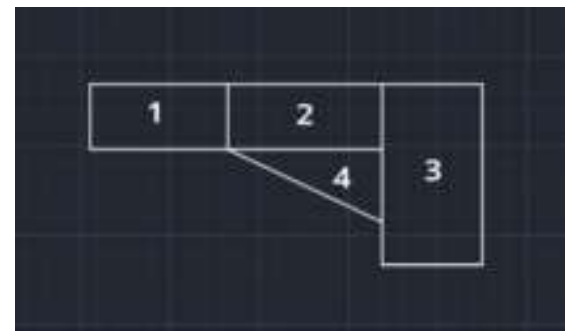

Fig 4:- Lower tank

2) $\mathrm{L} \times \mathrm{B} \times \mathrm{H}$

$=0.27 \times 0.52 \times 0.16$

$=0.0224 \mathrm{~m} 3$

3) $\mathrm{L} \times \mathrm{B} \times \mathrm{H}$

$=0.2 \times 0.52 \times 0.48$

$=0.04992 \mathrm{~m} 3$

4) $(\mathrm{L} \times \mathrm{B} \times \mathrm{H}) \times 0.5$

$=0.0105 \mathrm{~m} 3$

Hence the total volume of tank is $0.09946 \mathrm{~m} 3$ i.e. 99.4 liters.

\section{EXPERIMENTATION AND TESTING ON MACHINE}

1) FLOW RATE W.R.T TIME OBSERVATION

Some observation in terms of discharge with respect to time were taken as follows.

Table 1

\begin{tabular}{|l|l|l|}
\hline SR.NO & TIME(SEC) & FLOWRATE(L/S) \\
\hline 1 & 2 & 0.61 \\
\hline 2 & 3 & 0.915 \\
\hline 3 & 4 & 1.22 \\
\hline 4 & 5 & 1.525 \\
\hline 5 & 6 & 1.83 \\
\hline 6 & 7 & 2.135 \\
\hline 7 & 8 & 2.44 \\
\hline 8 & 9 & 2.745 \\
\hline 9 & 10 & 3.05 \\
\hline
\end{tabular}

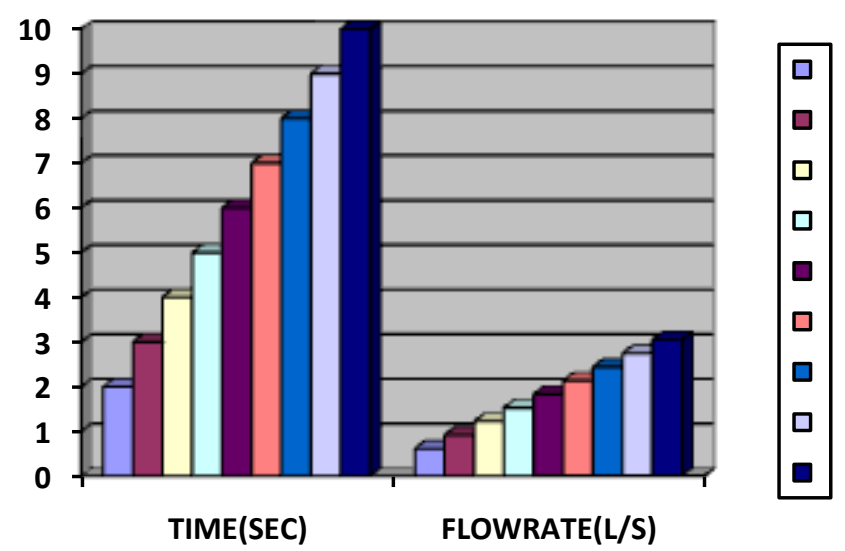

Graph1:- Behavior of Flowrate (Q) and Time (t)

\section{Result:}

Therefore, the flow rate and timing is

1) For the lower tank selecting $3 \mathrm{sec}$ and flow rate is $0.915 \mathrm{l} / \mathrm{s}$

2) For the upper tank selecting $5 \mathrm{sec}$ and flow rate of $1.525 \mathrm{l} / \mathrm{s}$. 
3) Therefore, the total time required is $8 \mathrm{sec}$ and total flow rate of water is $2.44 \mathrm{l} / \mathrm{s}$.

4) Therefore, the angle of shifter mechanism is:

5) $90^{\circ}$ for the direction of flow in tank.

6) $130^{\circ}$ for directing the flow out of the tank

VI. ACTUAL FABRICATED MODEL

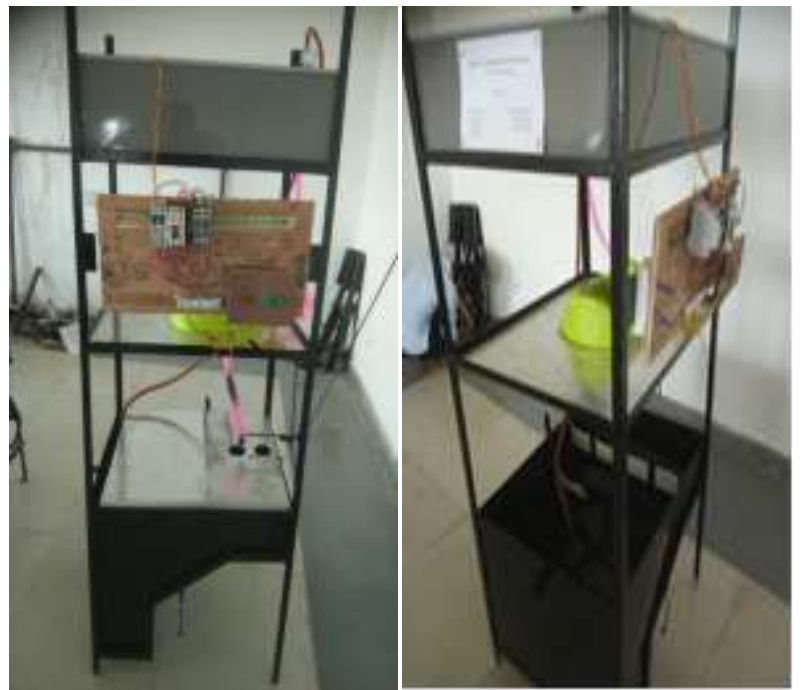

VII. CONCLUSION

As per the market survey we performed at Railway Green Toilet in Nagpur, we can conclude that the requirement of the shifter mechanism plays an important role while cleaning the toilet with harmful chemicals that would not destroy the bacteria present inside the Bio Digester. The pressurized flushing system will help in saving the large amount of water that could be require in train for other useful purposes. The water available at the outlet of the bio toilet can be used for re-flushing after passing from the filter which separates the particulates of waste from the water.

\section{REFERENCES}

[1] http://boingboing.net/2011/10/21/complaining-letter-that-got-toilets-installed-on-indias-trains.html

[2] https://www.researchgate.net/publication/272677957_SANITATION_PROBLEMS_IN_INDIAN_RAILWAYS

[3] http://www.merinews.com/article/sanitation-and-cleanliness-need-urgent-attention-in-indian-railways/126845.shtml

[4] https://indianrlynews.wordpress.com/tag/cdts-technology/

[5] http://www.downtoearth.org.in/coverage/indian-railways-experimentation-with-ecofriendly-toilets-4386

[6] www.biotoilet.org

[7] www.wockhardfoundation.org/pro-bio-toilet.aspx

[8] www.gogreensol.com/bio-digester.php 